\title{
TINJAUAN BUKU: MENYOAL KEDAULATAN INDONESIA DALAM FLIGHT INFORMATION REGION (FIR) INDONESIA-SINGAPURA
}

\author{
Achmad Ismail
}

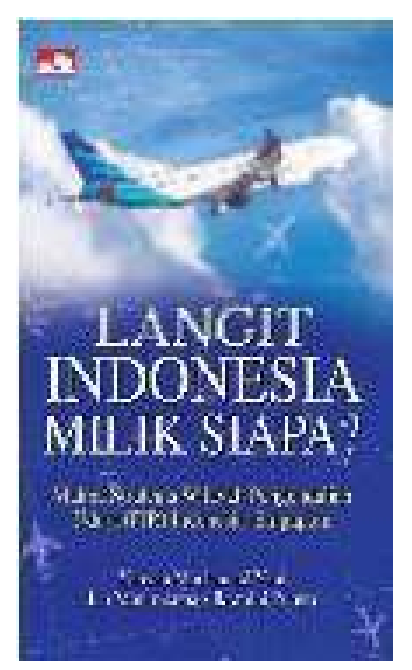

$\begin{array}{ll}\text { Judul } & \begin{array}{l}\text { : Langit Indonesia Milik siapa? } \\ \text { Makna Strategis Wilayah } \\ \end{array} \\ & \begin{array}{l}\text { Pengendalian Udara (FIR) } \\ \text { Indonesia-Singapura }\end{array} \\ \text { Tahun Terbit } \quad & 2017 \\ \text { Penerbit } & : \text { Elex Media Komputindo } \\ \text { Penulis } & : \text { Yanyan M. Yani, Ian Montratama } \\ & \text { \& Ikrardhi Putera } \\ \text { Jumlah Halaman : } & 176 \text { Halaman } \\ \text { ISBN } & : 978-602-04-0054-9\end{array}$

Pada abad ke-21 ini, konflik kedaulatan di udara tidak bisa dielakkan, terlebih banyak nilai strategis yang terdapat didalamnya. Sebagai contoh, selama 20 tahun lebih Indonesia dan Singapura memiliki kesepakatan bahwa Indonesia mendelegasikan zona identifikasi penerbangan (Flight Information Region/FIR) kepada Singapura. Hal ini bertujuan untuk meningkatkan kesadaran di udara sehingga pengaturan lalu lintas di udara lebih tertib. Dengan demikian, setiap pesawat yang melintasi kawasan tersebut haruslah meminta izin kepada Air Traffic Controller (ATC) di Singapura agar tidak terjadi kecelakaan. Namun isu negatif bagi Indonesia menyeruak ketika kendali FIR dibawah Singapura dapat mengganggu aktivitas pertahanan Indonesia. Oleh karenanya, Indonesia diibaratkan memiliki kedaulatan namun tidak berdaulat (Hakim, 2012). Hingga pada akhirnya Indonesia melakukan beberapa upaya untuk mengambil alih atas kendali FIR, mulai dari perundingan secara bilateral/multilateral hingga mengukur skenario perang udara dan postur kekuatan udara Indonesia. 
Poin-poin diataslah yang dijabarkan secara komprehensif oleh para penulis dalam buku yang berjudul "Langit Indonesia Milik siapa? Makna Strategis Wilayah Pengendalian Udara (FIR) Indonesia-Singapura." Buku ini menarik sebagai bahan bacaan akademisi HI dengan konsentrasi keamanan internasional serta akademisi dari prajurit TNI Angkatan Udara. Pun, buku ini ibarat "angin segar" sekaligus menambah literasi buku ilmiah yang membahas soal kedaulatan udara Indonesia dalam konteks FIR. Buku ini memiliki keunggulan yaitu mengingatkan kembali kepada para pembaca akan makna strategis dari FIR terhadap kedaulatan udara Indonesia yang mengaitkannya dengan konsep security dilemma dan balance of power terhadap Singapura serta berbagai upaya yang telah dilakukan pemerintah dalam mengambil alih kelola FIR.

Para penulis mengemas bahasan ini terlihat sangat komprehensif, terstruktur dan sistematis. Ini tersurat dari komposisi buku yang disusun. Setiap sub-bab nya selalu berfokus membedah makna strategis dari FIR dengan menggunakan pisau analisis melalui beberapa konsep dalam ilmu HI. Terlebih struktur bahasannya secara historis terbilang lengkap, mulai dari sejarah perjanjian FIR Indonesia-Singapura hingga upaya-upaya yang dilakukan Indonesia untuk mengambil alih pengelolaan FIR pada pemerintahan Presiden Joko Widodo. Pembabakan buku seperti inilah yang membuat para pembaca menjadi lebih paham memandang satu kasus dengan suatu konsep/teori HI. Diulasnya pula upaya-upaya yang dilakukan pemerintah dalam pengambilalihan pengelolaan FIR, membuat pembaca menjadi lebih paham sejauh mana progress yang telah dicapai oleh Indonesia.

Sebagaimana yang telah disinggung pada paragraf sebelumnya, buku ini mencoba menelaah implikasi pengelolaan FIR oleh Singapura dari aspek keamanan Indonesia dengan menggunakan sudut pandang security dilemma (perspektif realis) sebagai pisau analisis. Secara sederhana, alasan utama terjadinya security dilemma rasa takut dieksploitasi oleh 
negara lain (Jervis, 1978); rasa ketidakpercayaan satu sama lain atas sistem internasional yang anarkis dalam mencapai kepentingan nasional masing-masing (Genest, 2004). Maka dalam konteks perjanjian FIR, ketika penerbangan militer/non militer Singapura hendak memasuki zona FIR, hanya meminta izin kepada ATC Singapura. Lalu penerbangan militer/non militer Indonesia yang hendak melintasi zona FIR, harus mendapat izin dari ATC Singapura juga. Inilah yang dirasa menjadi ketakutan tersendiri bagi sistem pertahanan Indonesia. Dapat dibayangkan ketika semua aktivitas termasuk data informasi penerbangan militer/non militer Indonesia ketika melewati zona FIR harus meminta izin dari ATC Singapura, tentunya ini berdampak pada aktivitas pertahanan serta kedaulatan udara Indonesia. Padahal Starke (1989) menjelaskan dalam teori kedaulatan udara mengakui bahwa setiap negara memiliki kedaulatan lengkap dan eksklusif atas ruang udara diatas wilayahnya dan perairan teritorialnya.

Ketakutan dan ketidakpercayaan yang dirasakan oleh Indonesia atas pengelolaan FIR oleh Singapura terhadap aktivitas pertahanan serta kedaulatan udara Indonesia, maka Indonesia dirasa perlu untuk mengukur alutsista yang dimilikinya serta dibandingkan dengan Singapura agar terbentuk balance of power. Secara umum balance of power is predicated on the notion that states seek to survive as independent entities (T. V. Paul, 2004). Entitas yang bebas inilah yang coba dikejar oleh negara untuk mendapatkan power di tengah sistem global yang anarki, jika tidak maka negara tersebut bisa menjadi tunduk terhadap negara lain dan kehilangan keamanan dan kemakmurannya. Kekuatan militer dan sumber daya ekonomi menjadi karakteristik objektif yang menentukan kemampuan sekaligus menjadi peran sentral dalam menetapkan posisi kekuatan utama (Odgaard, 2007). Buku ini pula menjabarkan sekaligus membandingkan alutsista yang dimiliki oleh Indonesia dan Singapura. Secara umum, alutsista Singapura lebih unggul dengan teknologi 
canggihnya khususnya di matra udara. Di sisi lain anggaran belanja militer Singapura lebih besar yaitu 3,44 \% dari PDB, sementara Indonesia masih berada di 0,88 \% dari PDB. Terlebih Singapura memiliki pakta pertahanan dengan Malaysia, Inggris, Australia dan Selandia Baru dalam kerangka Five Power Defense Arrangment (FPDA). Sementara Indonesia memiliki keunggulan dalam bidang kuantitas personel yang lebih banyak kualitas yang lebih mumpuni.

Sebagaimana yang telah diungkap pada paragraf sebelumnya, buku ini pula menjelaskan skenario perang udara serta postur kekuatan udara yang ideal melihat fenomena dilemma keamanan dan perimbangan kekuatan Indonesia dan Singapura. Untuk mengantisipasi perang, maka Indonesia pertama dan utama yang harus dilakukan adalah melemahkan kekuatan eksternal Singapura terlebih dahulu yaitu meruntuhkan kredibilitas lengan FPDA serta alignment-nya dengan Amerika Serikat (AS). Caranya dengan memberikan persepsi terhadap negara anggota FPDA (kecuali Singapura) serta AS bahwa Indonesia bukanlah sebagai ancaman. Selanjutnya dengan melumpuhkan jet tempur siluman generasi ke-5 yang dimiliki Singapura dengan sistem radar pasif dan rudal pertahanan udara Indonesia. Selanjutnya Indonesia harus membeli jet tempur siluman dengan persepsi bukan untuk kekuatan internal semata tetapi untuk kekuatan eksternal juga. Dengan kata lain, Indonesia membeli jet tempur siluman dari AS dengan harapan membuat persepsi bahwa Indonesia bukanlah ancaman. Dalam konteks postur kekuatan udara yang ideal bagi Indonesia, metode kalkulasi tempur secara akademis digunakan sebagai alat analisis pembangunan kekuatan udara agar menyamai bahkan melebihi dari postur kekuatan udara Singapura.

Buku ini pula menjabarkan berbagai upaya yang telah ditempuh oleh Indonesia untuk mengambil alih kendali pengelolaan di zona FIR. Indonesia telah mempersiapkan cetak biru pengelolaan navigasi di zona FIR, telah membentuk skema pembiayaan, telah membentuk organisasi 
unit pelaksana FIR sekaligus melakukan lelang sistem navigasi dan mempersiapkan SDM yang mumpuni. Namun yang terpenting adalah Indonesia harus menjadi anggota dewan International Civil Aviation Organization (ICAO) agar dapat melobi pengambilalihan kendali di zona FIR. Pada kesimpulannya, buku ini menjadi literatur penting bagi penstudi ilmu HI dengan konsentrasi keamanan internasional. Pasalnya buku ini berhasil memberikan analisa mendalam tentang makna strategis FIR bagi Indonesia sekaligus mengaitkannya dengan konsep dilemma keamanan dan perimbangan kekuatan. Para penulis pula berhasil menjabarkan skenario perang udara dan postur kekuatan udara Indonesia yang ideal sebagai jawaban atas perimbangan kekuatan dengan Singapura.

\section{DAFTAR PUSTAKA}

Genest, Marc A. 2004. Conflict and Cooperation: Evolving Theories of International Relations $2^{\text {nd }}$ ed. Beldmon: Thompson Wadsworth

Hakim, Chappy. 2012. Quo Vadis Kedaulatan udara Indonesia?. Jakarta: Red and White Publishing

Jervis, Robert. 1978. Cooperation under the Security Dilemma. World Politics, Vol. 30 No. 2. hlm. 167-214

Odgaard, Liselotte. 2007. The Balance of Power in Asia-Pacific Security. New York: Routledge

Paul, T.V., Fortman, Michel, \& Wirtz, James J. 2004. Balance of Power: Theory and Practice in th $21^{\text {st }}$ Century. Stanford: Stanford University Press

Starke, J.G. 1989. Pengantar Hukum Internasional I. Jakarta: Sinar Grafika 